\title{
Pelapisan Bahan Magnetik Pasir Besi Bugel dengan Sitrat
}

\author{
Nur Mutia Rosiati ${ }^{*}$, Dikki Miswanda ${ }^{2}$, Muflikhah $^{3}$ \\ 1Program Studi Teknologi Pengolahan Kulit, Politeknik ATK Yogyakarta, Indonesia \\ 2,3Fakultas Matematika dan Ilmu Pengetahuan Alam, Universitas Gadjah Mada, \\ Yogyakarta, Indonesia \\ *mutiarosiati@kemenperin.go.id
}

\begin{abstract}
Abstrak
Pemanfaatan bahan alam sebagai sumber bahan magnetik (BM) memiliki keuntungan tersendiri, yakni preparasi yang lebih mudah dilakukan, jumlah bahan kimia yang digunakan lebih sedikit dan biaya preparasi lebih terjangkau. Modifikasi BM perlu dilakukan untuk mendukung perannya sebagai adsorben magnetik. Hasil penelitian membuktikan bahwa unsur terbanyak yang terkandung pada BM pasir besi Pantai Bugel adalah Fe, Ti dan Si dengan fasa oksida dominan berupa magnetit. Bahan magnetik pasir besi Pantai Bugel terlapis sitrat (BM/Sitrat) telah berhasil disintesis dengan metode perendaman pada penelitian ini. Variasi waktu perendaman BM dalam larutan sitrat dilakukan dengan waktu 6, 12 dan 24 jam untuk mengetahui waktu optimum perendaman. Hasil penelitian menunjukkan bahwa waktu optimum perendaman dicapai pada waktu 24 jam.
\end{abstract}

Kata kunci: bahan magnetik; sitrat; perendaman

\begin{abstract}
The use of natural materials as a source of magnetic material (MM) is a distinct advantage. It has easier preparation, less amount of chemicals used and more affordable preparation costs. Modification of MM was carried out to support its role as a magnetic adsorbent. The result proves that the most elements contained in MM of Bugel iron sand are Fe, Ti and Si with magnetite as its dominant oxide phase. The MM of Bugel iron sand coated with citrate (MM/Citrate) was successfully synthesized using immersion method in this study. Immersion times of citrate used were 6, 12 and 24 hours to determine the optimum immersion time. This study showed that the optimum immersion time was reached at 24 hours.
\end{abstract}

Keywords: magnetic materia; citrate; immersion

\section{Pendahuluan}

Dewasa ini adsorben magnetik menjadi salah satu jenis adsorben yang menarik untuk dikembangkan. Sifat kemagnetan yang dimilikinya dapat mempermudah proses pemisahan adsorben dengan filtrat. Adsorben magnetik dapat diperoleh melalui proses sintesis maupun bersumber dari alam. Banyak peneliti yang memperoleh adsorben magnetik melalui 
proses sintesis (Gaete dkk., 2019; Lu dkk., 2019). Hal ini berbeda dengan Prasdiantika

(2015) yang menggunakan adsorben magnetik dari pasir besi alam. Penggunaan pasir besi alam sebagai sumber bahan magnetik (BM) memiliki keuntungan dibandingkan dengan bahan magnetik sintetis, yakni preparasi yang lebih mudah dilakukan, jumlah bahan kimia yang digunakan lebih sedikit dan biaya preparasi lebih terjangkau. Oleh karena itu, bahan magnetik yang dikembangkan pada penelitian ini bersumber dari pasir besi alam.

Modifikasi bahan magnetik dengan gugus fungsi terbukti dapat meningkatkan kemampuan adsorpsi dari bahan magnetik (Nuryono dkk., 2014(a)). Proses modifikasi bahan magnetik pasir besi dilakukan pada penelitian ini dengan tujuan untuk mendukung perannya lebih lanjut sebagai adsorben magnetik. Gugus sitrat dipilih sebagai bahan modifikasi karena mengandung gugus karboksil yang memiliki pasangan elektron bebas (PEB) sehingga dapat berikatan dengan logam. Waktu perendaman BM dengan sitrat divariasi untuk mengetahui pengaruhnya terhadap jumlah gugus yang terikat pada BM.

\section{Metode Penelitian}

\section{Alat dan Bahan}

Alat yang digunakan pada penelitian ini terdiri dari beberapa jenis peralatan analisis dan peralatan penunjang. Karakterisasi BM pasir besi dilakukan dengan X-Ray Flourescence (PAnalytical Minipal 4), difraktometer sinar-X (Rigaku Multiflex) dan spektrofotometer inframerah (Shimadzu FTIR Prestige 21). Peralatan penunjang yang digunakan meliputi oven, timbangan analitik, medan magnet eksternal dan beberapa peralatan gelas.

Bahan magnetik pasir besi alam yang digunakan berasal dari pesisir pantai Bugel Kulon Progo DIY. Bahan lain yang digunakan adalah akuades dan natrium sitrat $0,5 \mathrm{M}$ (Merck).
Prosedur Kerja

Pasir besi sejumlah $10 \mathrm{~g}$ dipisahkan dengan medan magnet eksternal kemudian BM yang tertarik oleh magnet ditimbang.

Bahan magnetik diayak dengan ukuran 70 mesh dan dikarakterisasi dengan XRF, XRD dan FTIR. Padatan yang tertarik oleh magnet dicuci dengan akuades hingga bersih dan dikeringkan pada suhu $70-80^{\circ} \mathrm{C}$ hingga kering. Selanjutnya BM direndam dengan akuades dan disonikasi selama 15 menit. BM dipisahkan dengan medan magnet eksternal dan dikeringkan pada suhu 70$80^{\circ} \mathrm{C}$ hingga kering. Padatan $\mathrm{BM}$ yang diperoleh dikarakterisasi dengan XRF, XRD dan FTIR.

Pelapisan BM dengan sitrat dilakukan dengan merendam sejumlah BM dalam $100 \mathrm{~mL}$ larutan natrium sitrat 0,5 M dengan variasi waktu perendaman 6,12 dan 24 jam. Kemudian padatan dipisahkan dan dikeringkan pada suhu $70-80^{\circ} \mathrm{C}$ hingga kering. Padatan BM yang diperoleh dikarakterisasi dengan FTIR.

\section{Hasil Penelitian dan Pembahasan}

Pemisahan antara BM dengan bahan non-magnetik dilakukan dengan cara memisahkan pasir besi dengan medan magnet eksternal. Hasil menunjukkan bahwa BM yang terkandung pada pasir besi alam Pantai Bugel adalah sebesar 86,19\% $\pm 1,60 \%$ (Tabel 1.). Persentase BM pada pasir besi ini merepresentasikan bahwa sebagian besar kandungan pasir besi alam Pantai Bugel merupakan BM.

Tabel 1. Kandungan BM pada Pasir Besi Bugel

\begin{tabular}{cc}
\hline $\begin{array}{c}\text { Percobaan } \\
\text { ke- }\end{array}$ & $\begin{array}{c}\text { Kandungan Bahan } \\
\text { Magnetik }(\%)\end{array}$ \\
\hline 1 & 85,51 \\
2 & 84,48 \\
3 & 85,97 \\
4 & 88,80 \\
\hline Rata-rata & $\mathbf{8 6 , 1 9}$ \\
\hline
\end{tabular}


Bahan magnetik yang diperoleh dari pasir besi Pantai Bugel dicuci dengan akuades kemudian disonikasi di dalam akuades dengan tujuan untuk menghilangkan pengotor pada BM. Pengotor ini merupakan bahan non-magnetik berukuran kecil yang bercampur dengan BM, seperti debu atau pasir. Oleh karena itu, bahan non-magnetik ini juga ikut tertarik magnet ketika dilakukan pemisahan dengan magnet eksternal dan hilang setelah dilakukan preparasi dengan akuades. Hilangnya pengotor ini dibuktikan dengan berkurangnya berat BM setelah dilakukan pencucian dengan akuades (Tabel 2.).

Tabel 2. Perubahan Berat BM Setelah Pencucian

\begin{tabular}{lc}
\hline \multicolumn{1}{c}{ Perlakuan } & Berat BM (g) \\
\hline $\begin{array}{l}\text { Pemisahan dari bahan } \\
\text { non-magnetik }\end{array}$ & 8,62 \\
Pencucian dengan akuades & 8,49 \\
\hline
\end{tabular}

Berdasarkan hasil analisis XRF yang tersaji pada Tabel 3. diketahui bahwa unsur yang paling banyak terkandung dalam BM pasir besi Pantai Bugel adalah Fe, kemudian diikuti dengan Ti dan Si. Keberadaan Fe dan Ti inilah yang menjadikan BM pasir besi Pantai Bugel berpotensi sebagai adsorben magnetik.

Tabel 3. Kadar Unsur pada BM

\begin{tabular}{ccc}
\hline \multirow{2}{*}{ Unsur } & \multicolumn{2}{c}{ Kadar (\%) } \\
\cline { 2 - 3 } & Awal & Pencucian \\
\hline $\mathrm{Fe}$ & 83,89 & 81,65 \\
$\mathrm{Ti}$ & 5,96 & 5,80 \\
$\mathrm{Si}$ & 3,50 & 3,80 \\
$\mathrm{Ca}$ & 1,57 & 1,89 \\
$\mathrm{Al}$ & 1,50 & 2,60 \\
$\mathrm{Bi}$ & 0,74 & 0,66 \\
$\mathrm{Eu}$ & 0,67 & 0,59 \\
$\mathrm{Mn}$ & 0,61 & 0,63 \\
$\mathrm{~V}$ & 0,48 & 0,50 \\
$\mathrm{Rb}$ & 0,47 & 0,39 \\
$\mathrm{P}$ & 0,38 & 0,40 \\
$\mathrm{Re}$ & 0,30 & 0,20 \\
$\mathrm{~K}$ & 0,25 & 0,30 \\
$\mathrm{Cr}$ & 0,10 & 0,09 \\
$\mathrm{Zn}$ & 0,08 & 0,09 \\
$\mathrm{Ni}$ & 0,08 & 0,08 \\
$\mathrm{Br}$ & & 0,26 \\
$\mathrm{Yb}$ & & 0,04 \\
\hline
\end{tabular}

Difraktogram hasil analisis diperlihatkan pada Gambar 1. Jika dibandingkan dengan Powder Diffraction File (PDF), BM mengandung berbagai jenis oksida besi. Hal ini dapat diketahui dari munculnya puncak-puncak yang karakteristik dari masing-masing oksida besi. Fasa oksida besi yang dominan pada $\mathrm{BM}$ ini adalah magnetit $\left(\mathrm{Fe}_{3} \mathrm{O}_{4}\right)$ sesuai dengan PDF No. 19-0629. Puncak karakteristik tersebut teramati pada sudut difraksi $(2 \theta) 18,40^{\circ} ; 30,26^{\circ} ; 35,58^{\circ} ; 43,24^{\circ}$; $53,66^{\circ} ; 57,16^{\circ}$ dan $62,62^{\circ}$ untuk BM sebelum pencucian serta pada $18,24^{\circ} ; 30,08^{\circ} ; 35,42^{\circ}$; $43,08^{\circ} ; 53,38^{\circ} ; 56,92^{\circ}$ dan $62,48^{\circ}$ untuk BM setelah pencucian. Hasil serupa juga dilaporkan oleh Prasdiantika (2016) yang menggunakan pasir besi dari pantai Lansilowo, Konawe, Sulawesi Tenggara dimana kandungan utama pasir besi tersebut adalah fasa magnetit. Selain magnetit, fasa oksida besi lain yang terdeteksi pada difraktogram adalah oksida besi silika $\left(\mathrm{Fe}_{2,95} \mathrm{Si}_{0,05} \mathrm{O}_{4}\right)$ sesuai PDF No. 52-1140, oksida besi titania $\left(\left(\left(\mathrm{Fe}_{2,5} \mathrm{Ti}_{0,5}\right)_{1,04}\right) \mathrm{O}_{4}\right)$ sesuai PDF No. 51-1587 dan ilmenit $\left(\mathrm{Fe}_{2} \mathrm{TiO}_{3}\right)$ sesuai PDF No. 29-0733.

Difraktogram XRD menunjukkan hasil yang sesuai dengan hasil analisis XRF (Tabel IV.2) dimana memberi informasi bahwa sebagian besar unsur yang terkandung pada BM pasir besi adalah besi (Fe). Penurunan intensitas puncak-puncak difraksi terlihat setelah dilakukan pencucian (Gambar 1. (b)). Hal ini dapat terjadi karena berkurangnya sebagian unsur penyusun fasa oksida besi, seperti Fe.

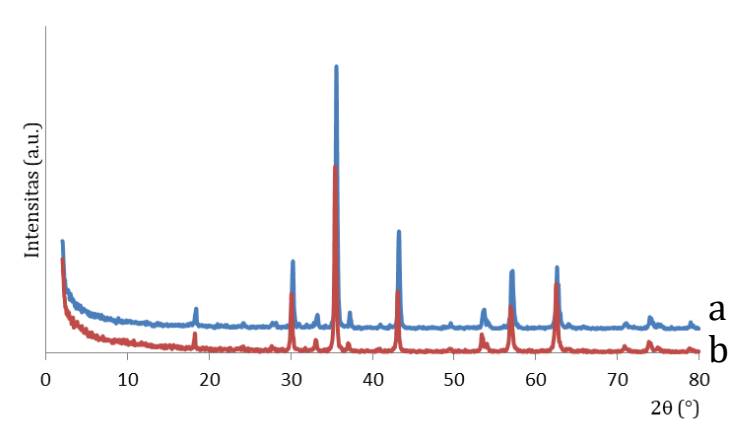

Gambar 1. Difraktogram BM: (a) Sebelum Pencucian dan (b) Setelah Pencucian

Spektra hasil analisis FTIR membuktikan bahwa tidak ada perubahan 
yang signifikan antara BM sebelum dan setelah pencucian (Gambar 2. (a) dan (b)). Hal ini menunjukkan tidak ada perubahan gugus fungsi setelah pencucian dilakukan. Pita vibrasi pada bilangan gelombang 571 $\mathrm{cm}^{-1}$ merupakan serapan yang berasal dari ikatan Fe-O (Nuryono dkk., 2019). Vibrasi ulur ikatan $\mathrm{M}-\mathrm{O}-\mathrm{M}$ dimana $\mathrm{M}$ adalah $\mathrm{Si}$ atau Ti teramati pada daerah bilangan gelombang 1041-1080 $\mathrm{cm}^{-1}$. Pita serapan pada daerah bilangan gelombang $3448 \mathrm{~cm}^{-1}$ muncul akibat adanya vibrasi ulur dari ikatan $-\mathrm{OH}$.

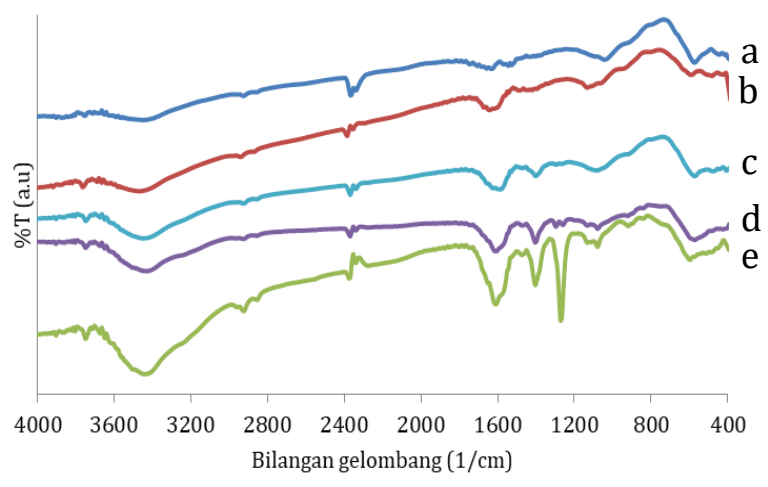

Gambar 2. Spektra FTIR: (a) BM Sebelum

Pencucian; (b) BM Setelah Pencucian; (c) BM/Sitrat-6 jam; (d) BM/Sitrat-12 jam dan (e) BM/Sitrat-24 jam

Keberhasilan proses pelapisan BM dengan sitrat dapat diketahui dari munculnya pita serapan baru pada spektra inframerah. Vibrasi C-O dari sitrat teramati pada daerah bilangan gelombang 1273-1297 $\mathrm{cm}^{-1}$. Serapan pada 1404-1412 $\mathrm{cm}^{-1}$ mengindikasikan adanya vibrasi ulur simetri gugus karboksil pada sitrat (Chen dkk., 2014). Pita serapan dari vibrasi ulur asimetri ikatan $\mathrm{C}=0$ muncul pada daerah bilangan gelombang 1582-1612 $\mathrm{cm}^{-1}$ (Na dkk., 2014). Pita serapan ini berhimpitan dengan vibrasi tekuk ikatan $\mathrm{O}-\mathrm{H}$. Adanya ikatan $\mathrm{C}-\mathrm{H}$ pada gugus sitrat mengakibatkan terbentuknya pita serapan pada bilangan gelombang 2924 $\mathrm{cm}^{-1}$ (Nuryono dkk., 2014(b)). Intensitas pita-pita serapan karakteristik dari gugus sitrat ini meningkat seiring dengan meningkatnya waktu perendaman yang digunakan. Hal ini menunjukkan bahwa semakin lama waktu perendaman maka semakin banyak jumlah gugus sitrat yang terikat pada permukaan BM. Oleh karena itu, waktu perendaman optimum yang diperoleh adalah 24 jam.

\section{Simpulan}

Berdasarkan hasil penelitian ini dapat disimpulkan bahwa unsur terbanyak yang terkandung pada BM pasir besi Pantai Bugel adalah $\mathrm{Fe}$, Ti dan $\mathrm{Si}$ dengan fasa oksida dominan berupa magnetit. Pelapisan BM dengan sitrat berhasil dilakukan melalui proses perendaman. Semakin lama waktu perendaman BM di dalam larutan sitrat mengakibatkan semakin banyak pula jumlah gugus sitrat yang terikat pada permukaan BM. Hasil penelitian menunjukkan bahwa waktu optimum perendaman dicapai pada waktu 24 jam.

\section{Daftar Pustaka}

Chen, Y., Gu, W., Pan, H., Jiang, S. dan Tang, R. 2014. Stabilizing Amorphus Calcium Phosphate Phase by Citrate Adsorption. CrystEngComm. 16, 1864-1867.

Gaete, J., Molina, L., Alfaro, I., Yanez, J., Valenzuela, F. dan Basualto, C., 2019. Recovery and Separation of Rhenium and Molybdenum from Aqueous Solutions that Simulate Mine Waters using Magnetite Nanoparticles Functionalized with AmineDerivative Groups. Miner. Eng. 136, 66-76.

Lu, M., Zhang, Y., Zhou, Y., Su, Z., Liu, B., Li, G. dan Jiang, T., 2019, AdsorptionDesorption Characteristics and mechanisms of $\mathrm{Pb}(\mathrm{II})$ on Natural Vanadium, Titanium-bearing Magnetite-Humic Acid. Powder Technol. 344, 947-958.

Na, Y., Yang, S. dan Lee, S. 2014. Evaluation of Citrate-Coated Magnetic Nanoparticles as Draw Solute for Forward Osmosis. Desalination. 347, 34-42. 
Nuryono, Muliaty, E., Rusdiarso, B., Sakti, S.C.W. dan Tanaka, S. 2014a, Adsorption of $\mathrm{Au}(\mathrm{III}), \mathrm{Cu}(\mathrm{II})$ and $\mathrm{Ni}(\mathrm{II})$ on Magnetite Coated with Mercapto Groups Modified Rice Hull Ash Silica. J.Ion Exchange. 25(4), 114121.

Nuryono, Rosiati, N.M., Rusdiarso, B., Sakti, S.C.W. dan Tanaka, S. 2014b. Coating of Magnetite with Mercapto Modified Rice Hull Ash Silica in a One-Pot Process. Springerplus. 3, 515.

Nuryono, Rosiati, N.M., Rettob, A.L., Suyanta dan Arryanto, Y. 2019. Coating of 2Aminobenzimidazole and 1-(oTolyl)biguanide Functionalized

Silicas on Iron Sand Magnetic Material for Sorption of $\left[\mathrm{AuCl}_{4}\right]^{-}$. Indo. J. Chem. 19(2), 395-404.

Prasdiantika, R. 2015. Sintesis Hibrida Propildietilentriamin-Silika Terlapis pada Bahan Magnetik Pasir Besi untuk Adsorpsi Au(III). Tesis, tidak 